\title{
Non-surgical Treatment for Cauda Equina Syndrome after Lumbar Epidural Block
}

\author{
Jin-Woo Park, Junseok W Hur, Jang-Bo Lee, Jung-Yul Park \\ Department of Neurosurgery, Korea University Anam Hospital, Korea University College of Medicine, Seoul, Korea
}

\begin{abstract}
Lumbar epidural block is an important modality to manage degenerative spinal disease. Although the procedure related complication rate is low, cauda equina syndrome after epidural block rarely occurs. Herein we discuss a case of block related cauda equina syndrome without any thecal sac compressive lesion. A 50 years old woman have been suffered from bilateral buttock pain and claudication. She was diagnosed as L4/5 spinal stenosis and L5/S1 herniation of intervertebral disc (HIVD). Lumbar epidural block has been performed from other clinic, however, neurologic deterioration developed subsequently; bilateral lower extremities paresthesia/weakness (G4), perineal numbness, and urinary incontinence. After transfer to our institute, we conducted magnetic resonance image (MRI) and confirmed there was no neural compressive lesion. After 3 days conservative treatments, perineal numbness gradually improved but paresthesia and both leg weakness remained. After one week, selective nerve root block (SNRB) was performed carefully and the patient showed improvement of symptoms by about 70\%. Second SNRB was performed one week after first SNRB. After the second SNRB, the symptom improved enough to withstand. The patient still complained of mild bilateral both leg pain after discharge. Two months later, the patient underwent radiofrequency rhizotomy and the symptoms fully recovered. In case of cauda equina subsequent to block without any thecal sac compressive lesion, could be treated with non-operative modalities.
\end{abstract}

Key Words: Cauda equina; Epidural; Nerve block; Complication

$\triangle$ Corresponding Author: Jung-Yul Park, Department of Neurosurgery, Korea University Anam Hospital, Korea University College of Medicine 73, Inchon-ro, Seongbuk-gu, Seoul 02841, Korea. Tel: +82-2-920-6743, Fax: +82-2-929-0629, E-mail: jypark98@korea.ac.kr

\section{INTRODUCTION}

Among various modalities to treat spine degenerative disease, epidural block has been reported as an effective and safe method for pain control ${ }^{2,13,18,19)}$. Nonetheless, epidural block implies some complications. These include increased neurological deterioration/paralysis/quadriplegia, intravascular injections (7.9-11.6\%), cerebrospinal fluid (CSF) fistulas $(0.4-6 \%)$, persistent positional headaches (28\%), arachnoiditis (6-16\%), hydrocephalus, air embolism, urinary retention, allergic reactions, intravascular injections (7.9-11.6\%), stroke, blindness, neurological deficits/paralysis, hematomas, seizures, and death ${ }^{1,4,5,8-12)}$. Among them, some complications require urgent treatments. Herein we report a case of cauda equina syndrome subsequent to block and suggest a non-surgical treatment as a tolerable option.

\section{CASE REPORT}

A 50 years old female patient suffered from bilateral buttock pain and claudication for 2 years. She was diagnosed as spinal stenosis L4/5 and HIVD L5/S1 after magnetic resonance image (MRI) work up (Fig. 1) She underwent epidural block for bila- teral lumbar 5 roots at other hospital. Immediate after the procedure, bilateral lower extremities paresthesia/weakness (grade 4), perineal numbness and urinary incontinence occurred suddenly and transferred to our institute urgently. Cauda equina syndrome was strongly suspected so the MRI was performed immediately. However, there was no evidence of thecal sac compression or marked change compared to previous MRI (Fig. 2). Absolute bed rest, fluid therapy, and pain killers such as opioid patch and NSAIDs were prescribed. After 3 days, perineal numbness and the weakness gradually improved. One week later, patient could walk without aid, however, paresthesia and buttock

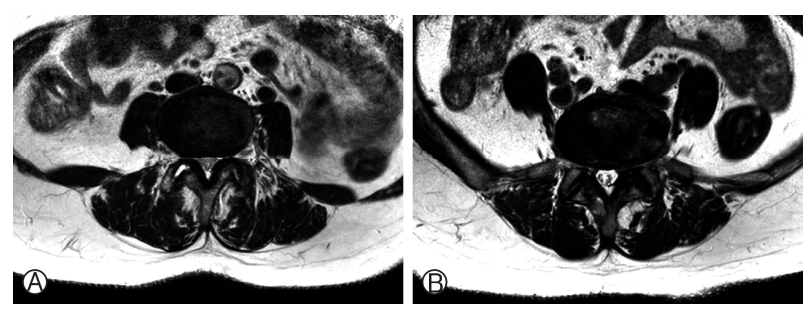

Fig. 1. A T2 weighted MR image before epidural block shows a hypertrophied ligament flavum and diffuse disc bulging at $L 4 / 5$ level $(A)$ and centrally herniated intervertebral disc at L5/ S1 level (B). 

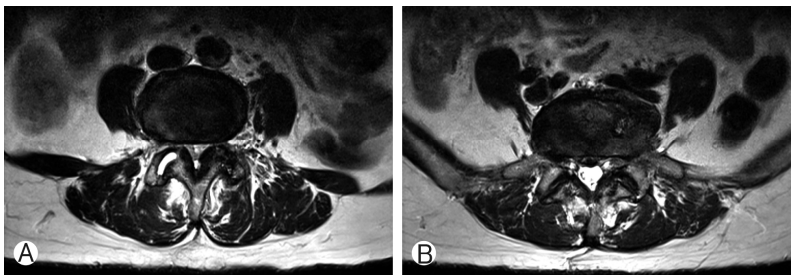

Fig. 2. A T2 weighted MR image performed in our institute after cauda equina symptom development. There is no definite interval change compare to previous MRI for both $L 4 / 5$ (A) and L5/S1 (B) levels.

pain showed no interval change. Pain was aggravated as time passed. One week after, SNRB was performed for unbearable pain, and paresthesia improved about $70 \%$ immediately. Second SNRB was performed one week after first SNRB. After the second SNRB, pain became tolerable with opioid patch single use and the patient could discharge. The patient complained of mild remnant bilateral leg pain at follow-up period. Two months after discharge, we performed radiofrequency rhizotomy and the symptom was almost relieved.

\section{DISCUSSION}

Lumbar degenerative pain is the second most common symptom for hospitalization and $13 \%$ of US citizens suffer at least once with this symptom and the epidural block is the most commonly performed procedure for the treatment ${ }^{16}$. The effectiveness of epidural block has also been reported in various studies in the treatment of degenerative lumbar pain ${ }^{2,13,18,19)}$. In a prospective study conducted by Riew et al., they reported that SNRB reduces the surgical treatment in patients who complain of disc herniation ${ }^{15}$.

In most cases, epidural block is performed under fluoroscopy guide for accuracy and safety. However, still the procedure rarely cause various complications. Typical complications includ e post-procedural headache, infection, and neurological paralysis ${ }^{1)}$. Neurologic deficit or deterioration is caused by intravascular injection or epidural hematoma ${ }^{19}$. Cauda equina syndrome is characterized by various degree of saddle anesthesia, sphincter dysfunction and paraplegia. Previous study reported that the main etiology of cauda equina syndrome was disc herniation (69\%), followed by tumor (16\%), trauma (10\%) and vascular $(5 \%)^{3,7,14)}$. Damage to nerve root of cauda equina following epidural block may occur due to disc or hematoma related root compression, inflammation, direct trauma and spinal ischemia due to neurotoxic drugs ${ }^{6}$. In our case, no specific root compression lesion or inflammation was detected in the MRI, so the most likely cause of cauda equina syndrome is drug-induced neurotoxicity or spinal ischemia.

Although the incidence of cauda equina syndrome after epidural block is low, physician should review the patient's under- lying disease and medical history carefully before procedure and observe patient closely after procedure. Generally, surgical treatment is important for symptomatic cauda equina syndrome, however, if the MRI show negative findings, non-surgical conservative management should be considered.

\section{CONCLUSION}

The cauda equina syndrome after neural blockade are not common, but once it occurs, an urgent situation develops. The mechanism of block related cauda equina differs so the MRI should be taken immediately. For compressive lesion, surgical treatment should be considered. However, if there is no compressive lesion, non-surgical treatment modalities as bed rest, fluid therapy, medication, delayed SNRB, and radiofrequency should be considered.

\section{REFERENCES}

1. Berger CW, Crosby ET, Grodecki W: North American survey of the management of dural puncture occurring during labour epidural analgesia. Can J Anaesth 45:110-114, 1998

2. Fukusaki M, Kobayashi I, Hara T, Sumikawa K: Symptoms of spinal stenosis do not improve after epidural steroid injection. Clin J Pain 14:148-151, 1998

3. Gardner A, Gardner E, Morley T: Cauda equina syndrome: a review of the current clinical and medico-legal position. Eur Spine J 20:690-697, 2011

4. Goodman BS, Posecion LW, Mallempati S, Bayazitoglu M: Complications and pitfalls of lumbar interlaminar and transforaminal epidural injections. Curr Rev Musculoskelet Med 1:212-222, 2008

5. Hooten WM, Kinney MO, Huntoon MA: Epidural abscess and meningitis after epidural corticosteroid injection. Mayo Clin Proc 79:682-686, 2004

6. Jain M, Srivastava U, Saxena S, Singh AK, Kumar A: Cauda equina syndrome following an uneventful spinal anaesthesia. Indian J Anaesth 54:68-69, 2010

7. Kostuik JP, Harrington I, Alexander D, Rand W, Evans D: Cauda equina syndrome and lumbar disc herniation. J Bone Joint Surg Am 68:386-391, 1986

8. Ludwig MA, Burns SP: Spinal cord infarction following cervical transforaminal epidural injection: a case report. Spine (Phila Pa 1976) 30:E266-268, 2005

9. Ma DJ, Gilula LA, Riew KD: Complications of fluoroscopically guided extraforaminal cervical nerve blocks. An analysis of 1,036 injections. J Bone Joint Surg Am 87:1025-1030, 2005

10. Manchikanti L, Cash KA, McManus CD, Pampati V, Fellows B: Results of 2-year follow-up of a randomized, double-blind, controlled trial of fluoroscopic caudal epidural injections in central spinal stenosis. Pain Physician 15:371-384, 2012

11. Manchikanti L, Malla Y, Wargo BW, Cash KA, Pampati V, Fellows B: Complications of fluoroscopically directed facet joint nerve blocks: a prospective evaluation of 7,500 episodes with 43,000 nerve blocks. Pain Physician 15:E143-150, 2012

12. Manchikanti L, Malla Y, Wargo BW, Cash KA, Pampati V, Fellows B: A prospective evaluation of complications of 10,000 fluoros- 
copically directed epidural injections. Pain Physician 15:131-140, 2012

13. Nelemans PJ, deBie RA, deVet HC, Sturmans F: Injection therapy for subacute and chronic benign low back pain. Spine (Phila Pa 1976) 26:501-515, 2001

14. O'Laoire SA, Crockard HA, Thomas DG: Prognosis for sphincter recovery after operation for cauda equina compression owing to lumbar disc prolapse. Br Med J (Clin Res Ed) 282:1852-1854, 1981

15. Riew KD, Yin Y, Gilula L, Bridwell KH, Lenke LG, Lauryssen $\mathrm{C}$, et al.: The effect of nerve-root injections on the need for operative treatment of lumbar radicular pain. A prospective, randomized, controlled, double-blind study. J Bone Joint Surg Am 82-A:
1589-1593, 2000

16. Rosas HG, Lee KS: Performing fluoroscopically guided interlaminar lumbar epidural injections. AJR Am J Roentgenol 199:419, 2012

17. Santosh Shridhar Borkar SK, Sumita Santosh Borkar, Samir Desai \& Priya Kulkarni: Efficacy of Selective Nerve Root Block in the Management of Prolapsed Intervertebral Disc. International Journal of Current Medical And Applied Sciences 14(1):6-10, 2017

18. Vad VB, Bhat AL, Lutz GE, Cammisa F: Transforaminal epidural steroid injections in lumbosacral radiculopathy: a prospective randomized study. Spine (Phila Pa 1976) 27:11-16, 2002

19. Weinstein SM, Herring SA, Nass: Lumbar epidural steroid injections. Spine J 3:37S-44S, 2003 